\title{
Sex-specific differences in survival after out-of-hospital cardiac arrest: a nationwide, population-based observational study
}

\author{
Yoshikazu Goto ${ }^{1 *}$, Akira Funada', Tetsuo Maeda', Hirofumi Okada and Yumiko Goto²
}

\begin{abstract}
Background: It remains unclear whether men have more favorable survival outcomes after out-of-hospital cardiac arrest (OHCA) than women.

Methods: We reviewed a total of 386,535 patients aged $\geq 18$ years with OHCA who were included in the Japanese registry from 2013 to 2016. The study endpoints were the rates of 1-month survival and neurologically intact survival (Cerebral Performance Category Scale score $=1$ or 2). Based on age, the reviewed patients were categorized into the following eight groups: <30, 30-39, 40-49, 50-59, 60-69, 70-79, 80-89, and $\geq 90$ years. The survival outcomes in men and women were compared using hierarchical propensity score matching.

Results: The crude survival rate was significantly higher in men than in women in five groups: 30-39, 40-49, 50-59, 60-69, and 70-79years (all $P<0.001$ ). Similarly, the crude neurologically intact survival rate was significantly higher in men than in women in seven groups: $<30,30-39,40-49,50-59,60-69,70-79$, and 80-89 years (all $P<0.005$ ). However, multivariate logistic regression analysis of each group revealed no significant sex-specific differences in 1-month survival outcomes (all $P>0.02$ ). Moreover, after hierarchical propensity score matching, the survival outcomes did not significantly differ between both sexes (all $P>0.05$ ).
\end{abstract}

Conclusions: No significant sex-specific differences were found in the rates of 1-month survival and neurologically intact survival after OHCA.

Keywords: Cardiopulmonary resuscitation, Out-of-hospital cardiac arrest, Sex difference, Epidemiology

\section{Background}

Location of arrest, younger age, presence of witnesses, bystander cardiopulmonary resuscitation (CPR), initial shockable rhythm, early defibrillation, short CPR duration, short emergency medical service (EMS) response time, and prompt coronary angiography with percutaneous coronary intervention if indicated are factors reportedly associated with survival in patients with outof-hospital cardiac arrest (OHCA) [1-5]. In terms of sex differences related to patient outcomes after OHCA, some studies reported that compared with men of the same age, women of childbearing age were independently associated with improved survival [6-14]; this

\footnotetext{
* Correspondence: gotoyosh@med.kanazawa-u.ac.jp

1 Department of Emergency and Critical Care Medicine, Kanazawa University Hospital, Takaramachi 13-1, Kanazawa 920-8640, Japan

Full list of author information is available at the end of the article
}

survival advantage might be attributable to the protective anti-apoptotic, anti-inflammatory, and mitochondriastabilizing activities of estrogen $[6,12,15]$. Other studies failed to demonstrate such an advantage but instead reported equal or worse survival rates or lower quality of life among female OHCA survivors [16-21]. Inconsistent results reported by previous observational studies may be due to differences in the study populations, EMS systems, and patient risk factors. A previous study reported differences in the baseline characteristics of women and men with OHCA. Compared with the women, the men were reportedly younger, and arrest was more frequently witnessed in the men than in the women; bystander CPR, cardiac etiology, and initial shockable rhythm were also more frequent in the men than in the women [12]. Rigorous statistical analysis is needed to confirm the differences in outcomes after

(C) The Author(s). 2019 Open Access This article is distributed under the terms of the Creative Commons Attribution 4.0 International License (http://creativecommons.org/licenses/by/4.0/), which permits unrestricted use, distribution, and 
OHCA between women and men. Therefore, in the present study, hierarchical propensity score matching was used to analyze and compare the outcomes after OHCA between age-stratified women and men who were included in a Japanese registry.

\section{Methods}

\section{Study design and setting}

This nationwide, population-based observational study included 386,535 adult patients aged $\geq 18$ years with OHCA. In all these patients, resuscitation was attempted by EMS personnel in Japan between January 1, 2013, and December 31, 2016. In Japan, nearly 127 million individuals reside in an area of approximately 380,000 $\mathrm{km}^{2}$. Further, approximately two thirds of Japan comprises uninhabited mountainous terrain [22]. The Fire and Disaster Management Agency (FDMA) of Japan supervises a nationwide EMS system, whereas local fire stations operate local EMS systems. In 2017, Japan had 732 fire departments and 5140 ambulance teams [23]. During the study period, all EMS personnel performed CPR following the Japanese CPR guidelines and attempted resuscitation by using automated external defibrillators, inserting airway adjuncts and peripheral intravenous catheters, and administering Ringer's lactate solution [23-25]. Only specially trained emergency lifesaving technicians are permitted to insert tracheal tubes and administer intravenous epinephrine after receiving online instructions from a physician [23]. Except in special situations, such as decapitation, incineration, decomposition, rigor mortis, and dependent cyanosis, EMS personnel in Japan are legally prohibited from terminating resuscitation in the field. Most patients with OHCA were given CPR by EMS personnel before transport to a hospital.

\section{Data collection and quality control}

In 2005, the FDMA launched an ongoing prospective population-based observational study including all patients with OHCA in Japan who received resuscitation by EMS personnel [23]. EMS personnel and the physician in charge at each center recorded data from the patients using an Utstein-style recommended guideline template $[26,27]$. The data were transferred to individual local fire stations and subsequently integrated into the registry on the FDMA database server. The database application automatically checked the patient data for consistency, which was again verified by the FDMA. The data were transferred to and stored in a nationwide database that was developed by the FDMA for public use. The FDMA granted us permission to access the anonymized data for this study.

The characteristics included in the dataset were as follows: patient sex and age, etiology of arrest, initially identified cardiac rhythm, presence and relation of bystander witnesses (e.g., family member, a layperson other than family, or EMS personnel), maneuver of bystander CPR, time of collapse, receipt of emergency calls, time of vehicle arrival at the scene and EMS initiation of CPR, 1-month survival, and neurologically intact survival. The etiology of arrest was presumed to be cardiac unless suitable evidence suggested a nonmedical cause (e.g., trauma, accidental hypothermia, hanging, drowning, drug overdose or poisoning, or asphyxia) or another noncardiac cause, such as respiratory or cerebrovascular disease or malignant tumors. The physicians in charge determined the etiology of arrest. Neurological outcomes were defined using the Cerebral Performance Category (CPC) Scale scores (1: good cerebral performance, 2: moderate cerebral disability, 3: severe cerebral disability, 4: coma or vegetative state, 5: death) [26]. The CPC scores were determined by the physician in charge.

\section{Study endpoints}

The primary study endpoint was neurologically intact survival (CPC Scale score $=1$ or 2 at 1 month). The secondary endpoint was 1-month survival after OHCA.

\section{Statistical analysis}

Continuous variables were either expressed as medians and 25th-75th percentiles or as means and standard deviation. Categorical variables were expressed as numbers and percentages. Effect size and variability were reported as odds ratios (ORs) with 95\% confidence intervals (CIs). To determine the differences in 1-month outcomes after OHCA based on sex, the patients were divided into the following eight groups: <30, 30-39, 40-49, 50-59, 60-69, $70-79,80-89$, and $\geq 90$ years. The Kruskal-Wallis and Dunn's post hoc tests were used to compare continuous variables. Chi-square test was used to compare categorical variables, and univariate logistic regression analysis was performed to compare the characteristics and outcomes between men and women. Multivariate logistic regression analyses were performed after adjusting for the differences in patient baseline characteristics for all unmatched patients and each age group for both matched and unmatched patients. Hierarchical propensity score matching was used to adjust for covariates when comparing the outcomes in men and women. Potential prehospital confounders in the analytic model were selected based on biological plausibility and data reported in previous studies. Multivariate logistic regression analysis in both matched and unmatched patients included the following 12 prehospital variables: calendar year (as a categorical variable), Japan geographic regions (rural or urban area), age (as a continuous variable), sex (men or women), presence of a witness (no witness, witnessed by family member, or nonfamily member), initial cardiac rhythm 
(shockable or nonshockable), cause of arrest (presumed cardiac cause or noncardiac cause), bystander CPR (yes or no), use of advanced airway management (yes or no), epinephrine administration (yes or no), EMS response time (as a continuous variable), and duration between the call to EMS and hospital arrival (as a continuous variable). Hierarchical propensity score matching analyses of the eight groups were performed using a logistic regression model that included the above-mentioned 12 variables (Additional file 1: Table S1-S8). One-to-one nearest neighbor matching was performed between men and women without replacement using a caliper width of 0.20 times of the standard deviation of the logit of the propensity score [28]. Before analyzing the outcomes, the success of the propensity matching procedure was determined by comparing the distributions of the patient characteristics in the matched sample by calculating an absolute standardized difference [29]. An absolute standardized difference of $\geq 0.1$ indicated a significant difference between the sexes [30]. The outcomes of the men and women in each age group were compared before propensity matching with either the chi-square test or Fisher's exact test and after propensity matching with the McNemar's test. All data were analyzed using JMP statistical package software version 14-Pro (SAS Institute Inc.; Cary, NC, USA). All the reported tests were two-tailed, and $P<0.005$ was considered statistically significant $[31,32]$.

\section{Results}

From 2013 to 2016, in Japan, the details of attempted resuscitation for 498,050 patients with OHCA were documented in the FDMA database. Figure 1 indicates the inclusion and exclusion criteria of the present study. Patients with nonmedical causes of OHCA (e.g., trauma, accidental hypothermia, hanging, drowning, drug overdose or poisoning, or asphyxia) and EMS-witnessed arrest, those without resuscitation attempted by EMS personnel, those aged $<18$ years, and those with unknown outcomes or age, were excluded. A group of 386,535 patients $(77.6 \%$ of those in the registry) met the inclusion criteria and were hence included in this study. Patient matching was achieved for $72.2 \%(279,080$ of 386,535$)$ of the patients $[64.3 \%(139,540$ of 217,173$)$ for men; $82.4 \%$ $(139,540$ of 169,362$)$ for women]. Propensity matching considerably improved the absolute standardized differences in each age group (Additional file 1: Table S1-S8).

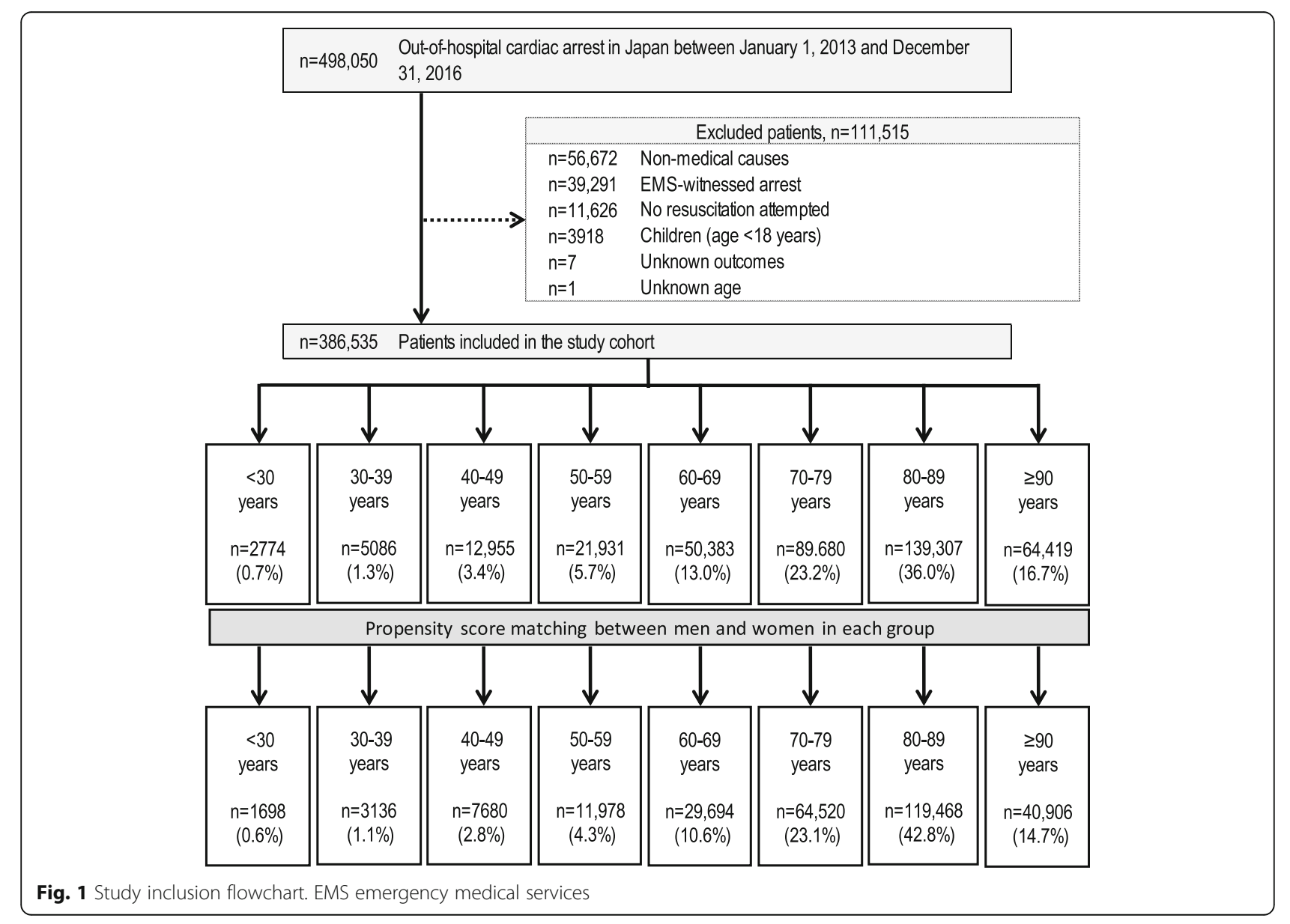


Table 1 presents the baseline characteristics of the women and men included in this study. Compared with the women, the included men were younger, less likely to experience OHCA in rural areas, and more likely to have a presumed cardiac origin and initial shockable rhythm; they were also more likely to be witnessed by a family member and receive advanced airway maintenance and epinephrine. In contrast, more women than men received bystander CPR following the instructions

Table 1 Baseline characteristics of the participants by sex

\begin{tabular}{llll}
\hline Characteristic & Men & Women & $P$ value \\
& $n=217,173$ & $n=169,362$ & \\
$(56.2 \%)$ & $(43.8 \%)$ &
\end{tabular}

\begin{tabular}{llll}
\hline Year & & & 0.95 \\
2013 & $53,459(24.6)$ & $41,693(24.6)$ & \\
2014 & $55,123(25.4)$ & $42,925(25.4)$ & \\
2015 & $54,061(24.9)$ & $42,294(24.9)$ & \\
2016 & $54,530(25.1)$ & $42,450(25.1)$ &
\end{tabular}

Geographic Japanese regions

\begin{tabular}{|c|c|c|c|}
\hline Rural area* & $54,143(24.9)$ & $43,512(25.7)$ & $<0.001$ \\
\hline \multicolumn{3}{|l|}{ Age, years } & \multirow[t]{3}{*}{$<0.001$} \\
\hline Mean (SD) & $74.3(14.1)$ & $80.3(13.2)$ & \\
\hline Median (25-75\%) & $77(67-85)$ & $84(75-90)$ & \\
\hline \multicolumn{4}{|l|}{ Etiology of cardiac arrest } \\
\hline Presumed cardiac cause & $152,531(70.2)$ & $116,994(69.1)$ & $<0.001$ \\
\hline Initial shockable rhythm & $23,159(10.7)$ & $7248(4.3)$ & $<0.001$ \\
\hline \multicolumn{3}{|l|}{ Bystander witness status } & \multirow[t]{4}{*}{$<0.001$} \\
\hline No witness & $129,709(59.7)$ & $107,825(63.7)$ & \\
\hline Family member & $57,967(26.7)$ & $35,544(21.0)$ & \\
\hline Nonfamily member & $29,497(13.6)$ & $25,993(15.3)$ & \\
\hline \multicolumn{4}{|l|}{ Dispatcher CPR instruction } \\
\hline Offered & $126,685(58.3)$ & $105,020(62.0)$ & $<0.001$ \\
\hline Bystander CPR & $107,618(49.6)$ & $95,609(56.4)$ & $<0.001$ \\
\hline $\begin{array}{l}\text { Use of advanced airway } \\
\text { management }\end{array}$ & $94,481(43.5)$ & $69,107(40.8)$ & $<0.001$ \\
\hline Epinephrine administration & $44,648(20.6)$ & $28,120(16.6)$ & $<0.001$ \\
\hline \multicolumn{3}{|l|}{ Call-to-response time, min } & \multirow[t]{3}{*}{$<0.001$} \\
\hline Mean (SD) & $9.2(3.9)$ & $9.1(3.6)$ & \\
\hline Median (25-75\%) & $8(7-11)$ & $8(7-11)$ & \\
\hline \multicolumn{3}{|c|}{ Call-to-hospital arrival time, min } & \multirow[t]{3}{*}{$<0.001$} \\
\hline Mean (SD) & $31.8(10.4)$ & $31.5(10.1)$ & \\
\hline Median (25-75\%) & $31(25-38)$ & $31(25-38)$ & \\
\hline \multicolumn{4}{|l|}{ 1-month outcome } \\
\hline Survival & $12,373(5.7)$ & $5,561(3.3)$ & $<0.001$ \\
\hline CPC 1 or 2 & $6936(3.2)$ & $2,327(1.4)$ & $<0.001$ \\
\hline
\end{tabular}

Values are reported as $n(\%)$ unless indicated otherwise. CPC, Cerebral Performance Category; $C P R$, cardiopulmonary resuscitation; $S D$, standard deviation *The rural area is constituted 19 prefectures with population of less than 200 inhabitants per $\mathrm{km}^{2}$ given by an EMS dispatcher. The overall crude 1-month survival outcomes were significantly better in men than in women. Multivariate logistic regression analysis in unmatched patients (Table 2) revealed that compared with women, men were independently associated with increased odds of achieving 1-month favorable outcomes (survival, adjusted OR $=1.07$; 95\% CI 1.03-1.11; CPC 1-2, adjusted $\mathrm{OR}=1.22$; $95 \% \mathrm{CI} 1.16-1.29$ ).

The crude 1-month survival outcomes in unmatched patients in each age group are presented in Additional file 2: Figure S1. Survival decreased with increasing age in both women and men (all $P$ for trend $<0.001$ ). The crude 1 -month survival rate was significantly higher in men than in women in five groups: $30-39,40-49,50-59$, 60-69, and 70-79 years. Multivariate logistic regression analysis revealed no significant sex-specific differences in the odds of 1-month survival (Fig. 2). The crude 1-month CPC 1-2 in the unmatched patients in each age group is shown in Additional file 3: Figure S2. The crude

Table 2 Adjusted odds ratios of prehospital variables for 1 -month outcomes in unmatched patients $(n=386,535)$

\begin{tabular}{|c|c|c|}
\hline \multirow[t]{2}{*}{ Variables } & \multicolumn{2}{|c|}{ Adjusted OR (95\% Cl) } \\
\hline & 1-month survival & 1-month CPC 1 or 2 \\
\hline \multicolumn{3}{|l|}{ Year } \\
\hline 2014 (vs. 2013) & $1.04(0.99-1.09)$ & $1.03(0.96-1.10)$ \\
\hline 2015 (vs. 2013) & $1.10(1.05-1.15)$ & $1.12(1.05-1.20)$ \\
\hline 2016 (vs. 2013) & $1.15(1.10-1.21)$ & $1.23(1.15-1.31)$ \\
\hline \multicolumn{3}{|l|}{ Geographic Japanese regions } \\
\hline Rural area* (vs. urban area) & $1.03(0.99-1.07)$ & $1.02(0.96-1.07)$ \\
\hline $\mathrm{Age}^{+}$ & $0.97(0.97-0.97)$ & $0.96(0.96-0.97)$ \\
\hline Men (vs. women) & $1.07(1.03-1.11)$ & $1.22(1.16-1.29)$ \\
\hline \multicolumn{3}{|c|}{ Witnessed arrest (vs. unwitnessed arrest) } \\
\hline Family member & $3.96(3.80-4.13)$ & $4.16(3.91-4.42)$ \\
\hline Nonfamily member & $4.86(4.65-5.08)$ & $5.49(5.16-5.85)$ \\
\hline $\begin{array}{l}\text { Initial shockable rhythm } \\
\text { (vs. initial nonshockable rhythm) }\end{array}$ & $7.31(7.03-7.60)$ & $9.17(8.70-9.65)$ \\
\hline $\begin{array}{l}\text { Presumed cardiac cause } \\
\text { (vs. noncardiac causes) }\end{array}$ & $0.79(0.76-0.82)$ & $1.37(1.29-1.46)$ \\
\hline $\begin{array}{l}\text { Bystander CPR } \\
\text { (vs. no bystander CPR) }\end{array}$ & $1.16(1.12-1.19)$ & $1.41(1.34-1.48)$ \\
\hline $\begin{array}{l}\text { Use of advanced airway } \\
\text { management (vs. no use } \\
\text { of airway management) }\end{array}$ & $0.69(0.67-0.72)$ & $0.42(0.40-0.44)$ \\
\hline $\begin{array}{l}\text { Epinephrine administration } \\
\text { (vs. no use of epinephrine) }\end{array}$ & $0.81(0.77-0.84)$ & $0.40(0.37-0.43)$ \\
\hline Call-to-response time $^{\dagger}$ & $0.91(0.90-0.91)$ & $0.90(0.89-0.90)$ \\
\hline Call-to-hospital arrival time $^{\dagger}$ & $0.99(0.99-1.00)$ & $1.00(0.99-1.00)$ \\
\hline
\end{tabular}

$\mathrm{Cl}$, confidence interval; $C P C$, Cerebral Performance Category; $C P R$, cardiopulmonary resuscitation; $O R$, odds ratio

*The rural area is constituted 19 prefectures with population of less than 200 inhabitants per $\mathrm{km}^{2}$

${ }^{\dagger}$ Adjusted odds ratios are reported for 1-year or 1-min increments 


\begin{tabular}{|cccc|}
\hline Group & Adjusted OR (95\% Cl) & $\boldsymbol{P}$ Value \\
\hline$<30 \mathrm{y}$ & $1.34(1.01-1.77)$ & 0.04 \\
$30-39 \mathrm{y}$ & $1.33(1.05-1.67)$ & 0.02 \\
$40-49 \mathrm{y}$ & $1.18(1.00-1.37)$ & 0.04 \\
$50-59 \mathrm{y}$ & $0.98(0.86-1.11)$ & 0.70 \\
$60-69 \mathrm{y}$ & $1.02(0.93-1.11)$ & 0.71 \\
$70-79 \mathrm{y}$ & $0.99(0.92-1.06)$ & 0.80 \\
$80-89 \mathrm{y}$ & $1.06(0.99-1.14)$ & 0.07 \\
$\geq 90 \mathrm{y}$ & $0.98(0.85-1.13)$ & 0.82 & \\
& & & \\
& & & \\
Fig. 2 Adjusted OR of women compared with men for 1-month survival in unmatched patients by age. Cl confidence interval, OR odds ratio
\end{tabular}

1-month CPC 1-2 gradually reduced with increasing age in both women and men (all $P$ for trend $<0.001$ ). The crude 1-month CPC $1-2$ were significantly higher in men than in women in seven groups: <30, 30-39, 40-49, 50$59,60-69,70-79$, and $80-89$ years. No significant differences in the 1-month CPC 1-2 were found between women and men after adjusting for confounders (Fig. 3). Figures 4 and 5 present the 1-month survival outcomes of matched patients in each age group. There were no significant sex-specific differences in the adjusted odds of survival and CPC 1-2 in any group.

\section{Discussion}

Hierarchical propensity score matching did not indicate any differences in the 1-month survival and neurologically intact survival between men and women in any of the age groups analyzed in this nationwide, populationbased observational study. This is the first large cohort study to clearly demonstrate the absence of differences in clinically meaningful survival between men and women after OHCA.

Hormonal effect on survival outcomes after cardiac arrest remains controversial: estrogen mediates hormonal responses to ischemia-reperfusion injury in women of childbearing age [33-37], whereas androgen mediates negative effects on the cardiovascular system in young men [38-40]. Previous studies have revealed that apart from reproductive roles, sex hormones possess cardioprotective and neuroprotective functions [41, 42]. Estrogen has previously been reported to have cardioprotective and neuroprotective effects after cardiac arrest [35-37]. Although the cardioprotective effects of estrogen are widely appreciated, little is known about the effects of progesterone [42]. Testosterone is associated with various adverse events in young men, including coronary plaque formation, platelet aggregation, inflammation, heart failure, and coronary artery disease [38-40]. Increased testosterone levels in men have been associated with decreased sudden cardiac arrest events; further, increased estradiol levels in both sexes have been associated with increased sudden cardiac arrest events [43]. Nevertheless, the impact of testosterone on the cardiovascular system remains controversial [42]. However, in the present study, there were no significant sex-specific differences in the 1-month survival outcomes in each age group after adjustment for prehospital confounders. These results possibly reflect estrogen-related effects on women and testosterone-related effects on men. Regarding the neuroprotective effects of sex hormones, estrogen reportedly slows down the progression of brain injury and diminishes the extent of cell death by suppressing apoptotic pathways [44]. In agreement with that report, another study demonstrated that brain edema after intracerebral hemorrhage-induced injury was reportedly less

\begin{tabular}{|cccc|}
\hline Group & Adjusted OR (95\% CI) \\
\hline$<30 \mathrm{y}$ & $0.98(0.69-1.41)$ & 0.93 \\
$30-39 \mathrm{y}$ & $0.98(0.74-1.30)$ & 0.88 \\
$40-49 \mathrm{y}$ & $1.06(0.88-1.28)$ & 0.53 \\
$50-59 \mathrm{y}$ & $0.82(0.70-0.98)$ & 0.03 \\
$60-69 \mathrm{y}$ & $0.91(0.80-1.02)$ & 0.10 \\
$70-79 \mathrm{y}$ & $0.91(0.82-1.01)$ & 0.07 \\
$80-89 \mathrm{y}$ & $0.96(0.86-1.08)$ & 0.48 \\
$\geq 90 \mathrm{y}$ & $0.91(0.71-1.18)$ & 0.48 \\
& & & \\
Fig. 3 Adjusted OR of women compared with men for 1-month CPC 1-2 in unmatched patients by age. Cl confidence interval, CPC Cerebral \\
Performance Category scale, OR odds ratio
\end{tabular}




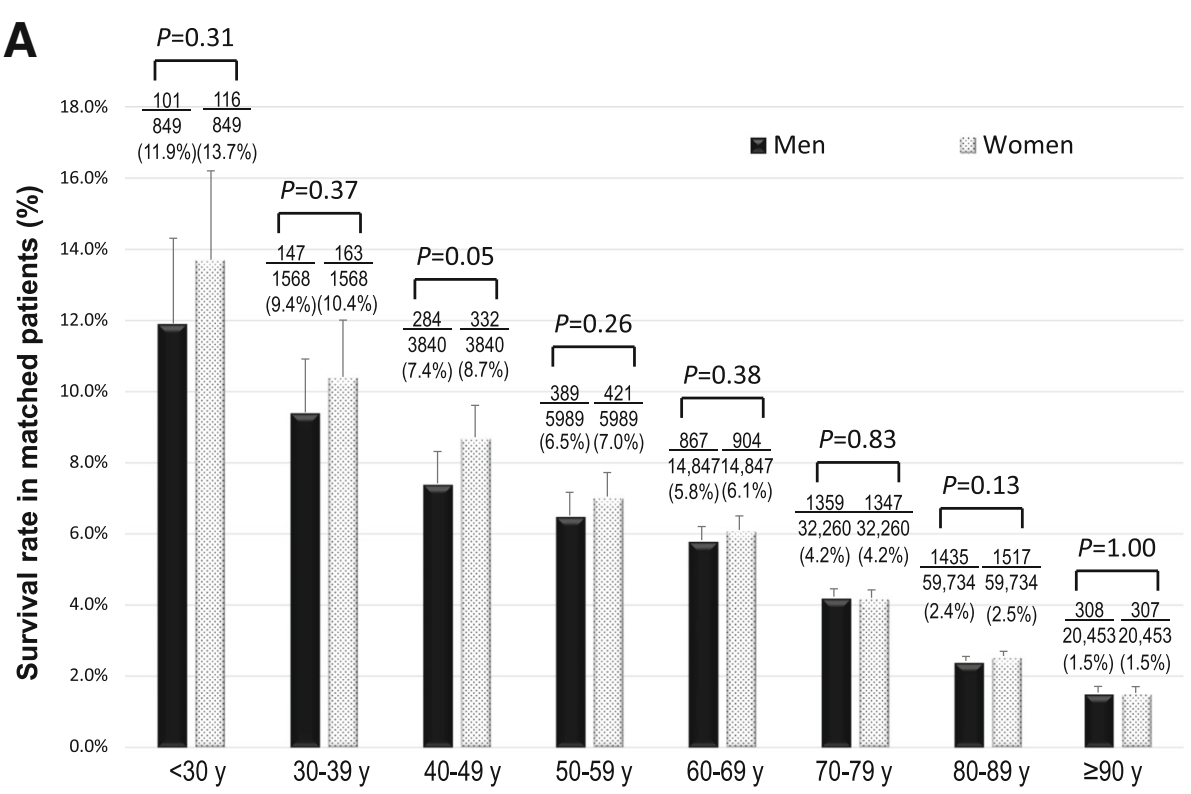

B

\begin{tabular}{lccc} 
Group & Adjusted OR $(\mathbf{9 5} \% \mathrm{Cl})$ & $\boldsymbol{P}$ Value \\
\hline$<30 \mathrm{y}$ & $1.25(0.89-1.76)$ & 0.19 \\
$30-39 \mathrm{y}$ & $1.14(0.87-1.50)$ & 0.33 \\
$40-49 \mathrm{y}$ & $1.22(1.01-1.47)$ & 0.04 \\
$50-59 \mathrm{y}$ & $1.09(0.93-1.27)$ & 0.30 \\
$60-69 \mathrm{y}$ & $1.04(0.94-1.15)$ & 0.49 \\
$70-79 \mathrm{y}$ & $1.00(0.92-1.08)$ & 0.99 \\
$80-89 \mathrm{y}$ & $1.07(0.99-1.15)$ & 0.07 \\
$\geq 90 \mathrm{y}$ & $0.99(0.84-1.16)$ & 0.91 & \\
& & &
\end{tabular}

Fig. 4 One-month survival rate in matched patients by age. a Survival rate. b Adjusted OR of women compared with men for 1-month survival. $\mathrm{Cl}$ confidence interval, OR odds ratio

severe in female than in male rats [45]. The neuroprotective properties of progesterone following cerebral ischemia, which are mediated by a reduction in edema, are most likely related to the suppression of interleukin- $1 \beta$ production [46]. Testosterone also possesses neuroprotective properties that result from the activation of androgen pathways as well as antioxidant and anti-apoptotic activities. The neuroprotective effects of sex hormones may thus partially explain the lack of significant differences in the neurologically intact survival outcomes between women and men in this study [41]. Other factors that may have contributed to the sex-specific differences in survival outcomes after OHCA include sex-specific anatomical differences of chest wall compliance [47], coronary risk factors [48], genomic variation [49], and care process [50]. The statistical analysis did not adjust for those factors as confounding variables because of the lack of data in the registry.

A recent analysis by Benjamin et al. proposed changing the significance level from $P<0.05$ to $P<0.005$ to avoid a high rate of false-positive results, even in the absence of other reporting problems [32]. Thus, the lack of reproducibility of sex differences and outcomes after OHCA in previous studies might be related to the statistical analysis. In this study, $P<0.005$ was considered statistically significant. Our findings that female patients with OHCA were older, were more likely to present with nonshockable rhythms, had more unwitnessed arrests, and received bystander CPR more frequently than male patients are consistent with the findings of some $[6,12,14,20]$ but not all previous studies $[8-11,16]$. Our findings showed that women of 


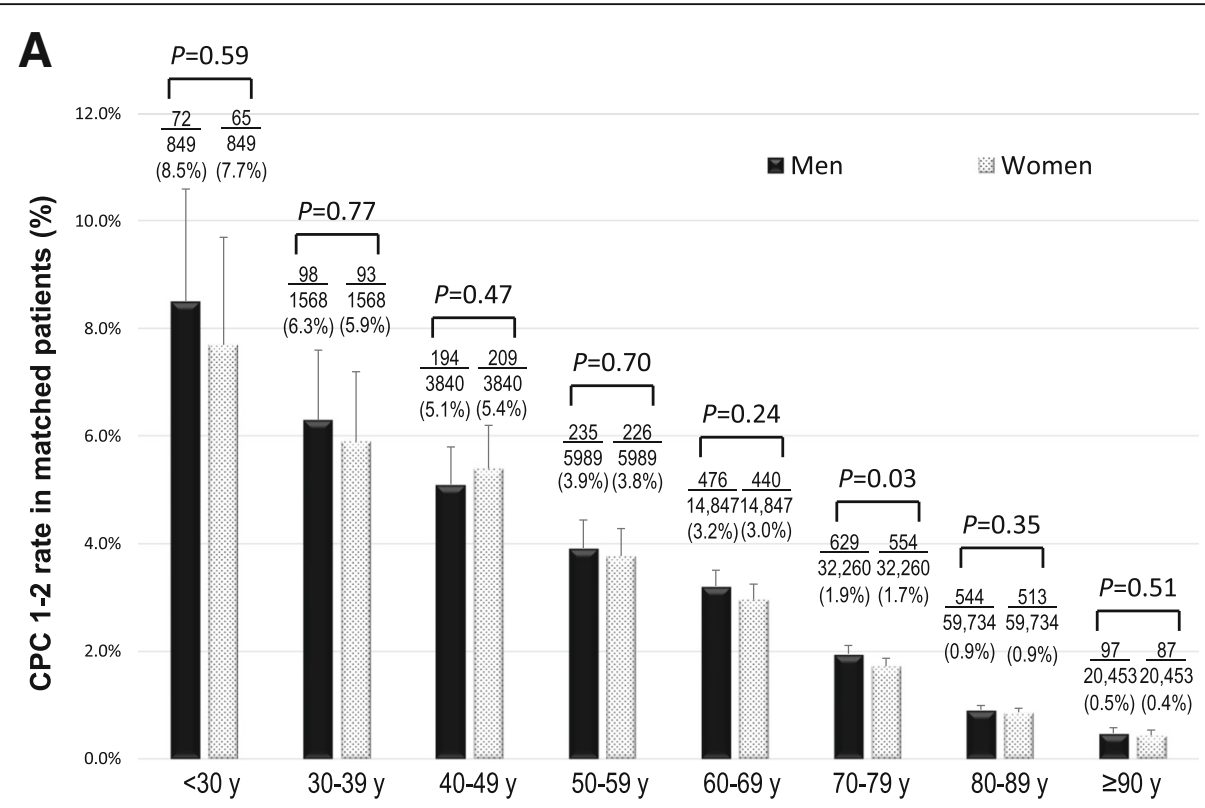

B

\begin{tabular}{lccc} 
Group & Adjusted OR (95\% Cl) & $\boldsymbol{P}$ Value & CPC 3-5 CPC 1-2 \\
\hline$<30 \mathrm{y}$ & $0.92(0.60-1.43)$ & 0.72 \\
$30-39 \mathrm{y}$ & $0.90(0.64-1.27)$ & 0.56 \\
$40-49 \mathrm{y}$ & $1.08(0.85-1.36)$ & 0.54 \\
$50-59 \mathrm{y}$ & $0.92(0.74-1.13)$ & 0.42 \\
$60-69 \mathrm{y}$ & $0.91(0.79-1.05)$ & 0.21 & 0.06 \\
$70-79 \mathrm{y}$ & $0.89(0.79-1.00)$ & 0.57 & 0.52 \\
$80-89 \mathrm{y}$ & $0.96(0.85-1.09)$ & & 0.4 Adjusted odds ratio $\left(95 \% \mathrm{Cl}{ }^{4}\right.$
\end{tabular}

Fig. 5 One-month CPC 1-2 rate in matched patients by age. a CPC 1-2 rate. b Adjusted OR of women compared with men for 1-month CPC 1-2. Cl confidence interval, CPC Cerebral Performance Category scale, OR odds ratio

childbearing age had no survival advantage over agematched men after OHCA, which differs from previously reported results in Japan $[6,7,14]$. For example, Kitamura et al. reported that from 1998 to 2007 in Osaka, female patients aged $>13$ years had higher 1-month survival rates and that those aged 13-49years had higher 1-month neurologically intact survival rates after OHCA compared with male patients of the same age [6]. Using the 20052007 Utstein data, Akahane et al. reported that female patients aged 30-79years with OHCA with an initial shockable rhythm had improved 1-month survival and that those aged 40-59 years had better 1-month neurologically intact survival than male patients of the same age [7]. Taken together, these findings indicate that the survival rates were not solely attributable to the effects of estrogen. In addition, we used hierarchical propensity score matching analysis within each age group to adjust for confounding factors; this was not followed by previous studies [6, 7]. Differences in the results reported in the above studies may also reflect improvements in the management OHCA after the 2010 and 2015 updates of the international CPR guidelines. Previous studies from Korea, Australia, and New Zealand reported no sex-specific differences in survival outcomes after OHCA, which is consistent with our results $[16,17,51]$. Importantly, our data further showed the relationship between sex and neurologically intact survival after cardiac arrest in which sex was not associated with clinically meaningful survival.

The present study has some limitations. First, the study analyzed data collected from a large national population by standard procedures; however, because of the retrospective observational design, we could not 
exclude uncontrolled confounders. For example, patient estrogen, progesterone, and testosterone levels were not available. Sex difference was a surrogate for both sex-related (sex hormone levels, autonomic modulation, and electrophysiological properties) and gender-specific (socioeconomic, environmental, educational, and community) factors that could not be adjusted for. A prospective study of patients with OHCA including sex hormone assays would be needed to clarify the relationship between sex hormone levels and outcomes. The present study also lacked data on pre-existing comorbidities, the location of arrest, the quality of bystander- and EMS-initiated CPR, and the in-hospital treatments. Even in propensity score matching analysis, we cannot exclude numerous unknown confounding factors that may mislead the sex-specific differences in the outcomes after OHCA. Other limitations are common to epidemiological studies, including ascertainment bias and lack of data integrity and validity. The relevance of our results to other communities with different emergency care systems and protocols is not known; similar studies in other countries would help validate our results.

\section{Conclusions}

The analyses of the Japanese nationwide registry revealed no significant sex-specific differences in the 1month survival and neurologically intact survival rates after OHCA.

\section{Additional files}

Additional file 1: Table S1. Baseline characteristics of unmatched and matched patients aged $<30$ years. Table S2. Baseline characteristics of unmatched and matched patients aged 30-39 years. Table S3. Baseline characteristics of unmatched and matched patients aged $40-49$ years. Table S4. Baseline characteristics of unmatched and matched patients aged 50-59 years. Table S5. Baseline characteristics of unmatched and matched patients aged 60-69 years. Table S6. Baseline characteristics of unmatched and matched patients aged 70-79years. Table S7. Baseline characteristics of unmatched and matched patients aged 80-89 years. Table S8. Baseline characteristics of unmatched and matched patients aged $\geq 90$ years. (DOCX $135 \mathrm{~kb}$ )

Additional file 2: Figure S1. One-month crude survival rate in unmatched patients by age ${ }^{*} P<0.001$. The trends of both sexes for increasing age groups were significant (all $P$ for trend $<0.001$ ). (PPTX $503 \mathrm{~kb}$ )

Additional file 3: Figure S2. One-month crude CPC 1-2 rate in unmatched patients by age CPC: Cerebral Performance Category scale. ${ }^{*} P<0.001 .{ }^{\dagger} P<0.005$. The trends of both sexes for increasing age groups were significant (all $P$ for trend $<0.001$ ). (PPTX $534 \mathrm{~kb}$ )

\section{Abbreviations}

Cl: Confidence interval; CPC: Cerebral Performance Category; CPR: Cardiopulmonary resuscitation; EMS: Emergency medical service: FDMA: Fire and Disaster Management Agency; OHCA: Out-of-hospital cardiac arrest; OR: Odds ratio

\section{Acknowledgements}

We thank all the EMS personnel and participating physicians in Japan and the Fire and Disaster Management Agency (FDMA) for their generous cooperation in establishing and maintaining the database.

\section{Authors' contributions}

YoG and AF designed the study. YoG, AF, TM, HO, and YuG sorted the data. YoG and YuG analyzed the data. YoG drafted the manuscript, and YuG and AF contributed substantially to its revision. YoG takes responsibility for the paper as a whole. All authors read and approved the final manuscript.

\section{Funding}

This work was supported by the Japan Society for the Promotion of Science (KAKENHI Grant No. 18 K09999), which had no role in the design and implementation of the study, the analysis and interpretation of the data, or the approval of the manuscript.

\section{Availability of data and materials}

The datasets generated during and/or analyzed during the current study are not publicly available because of the Fire and Disaster Management Agency (FDMA) regulations but are available from the corresponding author on reasonable request.

\section{Ethics approval and consent to participate}

This study was approved by the institutional review board of Kanazawa University (No. 1263). The requirement for written informed consent was waived considering the study involved the use of anonymized data.

\section{Consent for publication}

Not applicable.

\section{Competing interests}

The authors declare that they have no competing interests.

\section{Author details}

'Department of Emergency and Critical Care Medicine, Kanazawa University Hospital, Takaramachi 13-1, Kanazawa 920-8640, Japan. ²Department of Cardiology, Yawata Medical Center, Yawata I 12-7, Komatsu 923-8551, Japan.

Received: 12 April 2019 Accepted: 18 July 2019

Published online: 25 July 2019

References

1. Goto Y, Maeda T, Nakatsu-Goto Y. Neurological outcomes in patients transported to hospital without a prehospital return of spontaneous circulation after cardiac arrest. Crit Care. 2013;17:R274.

2. Goto Y, Funada A, Goto Y. Relationship between the duration of cardiopulmonary resuscitation and favorable neurological outcomes after out-of-hospital cardiac arrest: a prospective, nationwide, population-based cohort study. J Am Heart Assoc. 2016;5:e002819.

3. Goto Y, Funada A, Goto Y. Relationship between emergency medical services response time and bystander intervention in patients with out-of-hospital cardiac arrest. J Am Heart Assoc. 2018;7:e007568.

4. Sondergaard KB, Wissenberg M, Gerds TA, Rajan S, Karlsson L, Kragholm K, Pape M, Lippert FK, Gislason GH, Folke F, Torp-Pedersen C, Hansen SM. Bystander cardiopulmonary resuscitation and long-term outcomes in out-of-hospital cardiac arrest according to location of arrest. Eur Heart J. 2019;40:309-18.

5. Steg PG, Popovic B. Emergency coronary angiography after out-of-hospital cardiac arrest: is it essential or futile? Circ Cardiovasc Interv. 2018:11:e006804

6. Kitamura T, Iwami T, Nichol G, Nishiuchi T, Hayashi Y, Nishiyama C, Sakai T, Kajino K, Hiraide A, Ikeuchi H, Nonogi H, Kawamura T. Utstein Osaka project. Reduction in incidence and fatality of out-of-hospital cardiac arrest in females of the reproductive age. Eur Heart J. 2010:31:1365-72.

7. Akahane M, Ogawa T, Koike S, Tanabe S, Horiguchi H, Mizoguchi T, Yasunaga $H$, Imamura $T$. The effects of sex on out-of-hospital cardiac arrest outcomes. Am J Med. 2011;124:325-33.

8. Adielsson A, Hollenberg J, Karlsson T, Lindqvist J, Lundin S, Silfverstolpe J, Svensson L, Herlitz J. Increase in survival and bystander CPR in out-of-hospital shockable arrhythmia: bystander CPR and female gender are predictors of improved outcome. Experiences from Sweden in an 18-year perspective. Heart. 2011;97:1391-6.

9. Teodorescu C, Reinier K, Uy-Evanado A, Ayala J, Mariani R, Wittwer L, Gunson K, Jui J, Chugh SS. Survival advantage from ventricular fibrillation and pulseless electrical activity in women compared to men: the Oregon Sudden Unexpected Death Study. J Interv Card Electrophysiol. 2012;34:219-25. 
10. Johnson MA, Haukoos JS, Larabee TM, Daugherty S, Chan PS, McNally B, Sasson C. Females of childbearing age have a survival benefit after out-of-hospital cardiac arrest. Resuscitation. 2013;84:639-44.

11. Wissenberg M, Hansen CM, Folke F, Lippert FK, Weeke P, Karlsson L, Rajan S, Søndergaard KB, Kragholm K, Christensen EF, Nielsen SL, Køber L, Gislason GH, Torp-Pedersen C. Survival after out-of-hospital cardiac arrest in relation to sex: a nationwide registry-based study. Resuscitation. 2014;85:1212-8.

12. Bougouin W, Mustafic H, Marijon E, Murad MH, Dumas F, Barbouttis A, Jabre $P$, Beganton F, Empana JP, Celermajer DS, Cariou A, Jouven X. Gender and survival after sudden cardiac arrest: a systematic review and meta-analysis. Resuscitation. 2015:94:55-60.

13. Ng YY, Wah W, Liu N, Zhou SA, Ho AF, Pek PP, Shin SD, Tanaka H, Khunkhlai N, Lin $\mathrm{CH}$, Wong KD, Cai WW, Ong ME. PAROS clinical research network. Associations between gender and cardiac arrest outcomes in pan-Asian out-of-hospital cardiac arrest patients. Resuscitation. 2016;102:116-21.

14. Hagihara A, Onozuka D, Ono J, Nagata T, Hasegawa M. Age $\times$ gender interaction effect on resuscitation outcomes in patients with out-of-hospital cardiac arrest. Am J Cardiol. 2017;120:387-92.

15. Wigginton JG, Perman SM, Barr GC, McGregor AJ, Miller AC, Napoli AM, Safdar B, Weaver KR, Deutsch S, Kayea T, Becker L. Sex- and gender-specific research priorities in cardiovascular resuscitation: proceedings from the 2014 Academic Emergency Medicine Consensus Conference Cardiovascular Resuscitation Research Workgroup. Acad Emerg Med. 2014;21:1343-9.

16. Ahn KO, Shin SD, Hwang SS. Sex disparity in resuscitation efforts and outcomes in out-of-hospital cardiac arrest. Am J Emerg Med. 2012;30:1810-6.

17. Bray JE, Stub D, Bernard S, Smith K. Exploring gender differences and the oestrogen effect in an Australian out-of-hospital cardiac arrest population. Resuscitation. 2013:84:957-63.

18. Lindner TW, Langørgen J, Sunde K, Larsen Al, Kvaløy JT, Heltne JK, Draegni T, Søreide E. Factors predicting the use of therapeutic hypothermia and survival in unconscious out-of-hospital cardiac arrest patients admitted to the ICU. Crit Care. 2013;17:R147.

19. Karlsson V, Karlsson V, Dankiewicz J, Nielsen N, Kern KB, Mooney MR, Riker RR, Rubertsson S, Seder DB, Stammet P, Sunde K, Søreide E, Unger BT, Friberg H. Association of gender to outcome after out-of-hospital cardiac arrest--a report from the International Cardiac Arrest Registry. Crit Care. 2015;19:182.

20. Hagihara A, Onozuka D, Hasegawa M, Nagata T, Abe T, Nabeshima Y. Resuscitation outcomes of reproductive-age females who experienced out-of-hospital cardiac arrest. Eur Heart J Acute Cardiovasc Care. 2017;6:121-9.

21. Wachelder EM, Moulaert VR, van Heugten C, Verbunt JA, Bekkers SC, Wade DT. Life after survival: long-term daily functioning and quality of life after an out-of-hospital cardiac arrest. Resuscitation. 2009:80:517-22.

22. Statistics Bureau, Ministry of Internal Affairs and Communications Japan. Statistical handbook of Japan 2017. http://www.stat.go.jp/english/data/ handbook/index.html. Accessed 11 Jan 2019.

23. Ambulance Service Planning Office of Fire and Disaster Management Agency of Japan. Effect of first aid for cardiopulmonary arrest [in Japanese]. https://www.fdma.go.jp/publication/rescue/post.html. Accessed 11 Jan 2019.

24. Japan Resuscitation Council CPR Guidelines Committee. 2010 Japanese guidelines for emergency care and cardiopulmonary resuscitation. Tokyo: Health Shuppansha; 2011. (in Japanese)

25. Japan Resuscitation Council CPR Guidelines Committee. 2015 Japanese guidelines for emergency care and cardiopulmonary resuscitation. Tokyo: Igaku shoin; 2016. (in Japanese)

26. Jacobs I, Nadkami V, Bahr J, Berg RA, Billi JE, Bossaert L, Cassan P, Coovadia A, D'Este K, Finn J, Halperin H, Handley A, Herlitz J, Hickey R, Idris A, Kloeck W, Larkin GL, Mancini ME, Mason P, Mears G, Monsieurs K, Montgomery W, Morley P. Nichol G, Nolan J, Okada K, Perlman J, Shuster M, Steen PA, Sterz F, Tibballs J, Timerman S, Truitt T, Zideman D. Cardiac arrest and cardiopulmonary resuscitation outcome reports: update and simplification of the Utstein templates for resuscitation registries: a statement for healthcare professionals from a task force of the International Liaison Committee on Resuscitation (American Heart Association, European Resuscitation Council, Australian Resuscitation Council, New Zealand Resuscitation Council, Heart and Stroke Foundation of Canada, InterAmerican Heart Foundation, Resuscitation Councils of Southern Africa). Circulation. 2004;110:3385-97.

27. Perkins GD, Jacobs IG, Nadkarni VM, Berg RA, Bhanji F, Biarent D, Bossaert LL, Brett SJ, Chamberlain D, de Caen AR, Deakin CD, Finn JC, Gräsner JT, Hazinski MF, Iwami T, Koster RW, Lim SH, Huei-Ming Ma M, BF MN, Morley PT, Morrison $\sqcup$, Monsieurs KG, Montgomery W, Nichol G, Okada K, Eng Hock Ong M, Travers AH, Nolan JP, Utstein Collaborators. Cardiac arrest and cardiopulmonary resuscitation outcome reports: update of the Utstein Resuscitation Registry Templates for Out-of-Hospital Cardiac Arrest: a statement for healthcare professionals from a task force of the International Liaison Committee on Resuscitation (American Heart Association, European Resuscitation Council, Australian and New Zealand Council on Resuscitation, Heart and Stroke Foundation of Canada, InterAmerican Heart Foundation, Resuscitation Council of Southern Africa, Resuscitation Council of Asia); and the American Heart Association Emergency Cardiovascular Care Committee and the Council on Cardiopulmonary, Critical Care, Perioperative and Resuscitation. Circulation. 2015;132:1286-300.

28. Rosenbaum PR, Donald BR. Constructing a control group using multivariate matched sampling methods that incorporate the propensity score. Am Stat. 1985;39:33-8.

29. Austin PC. An introduction to propensity score methods for reducing the effects of confounding in observational studies. Multivariate Behav Res. 2011;46:399-424.

30. Normand ST, Landrum MB, Guadagnoli E, Ayanian JZ, Ryan TJ, Cleary PD, McNeil BJ. Validating recommendations for coronary angiography following acute myocardial infarction in the elderly: a matched analysis using propensity scores. J Clin Epidemiol. 2001;54:387-98.

31. Ioannidis JPA. The proposal to lower $P$ value thresholds to .005. JAMA. 2018;319:1429-30

32. Benjamin DJ, Berger JO, Johannesson M, Nosek BA, Wagenmakers EJ, Berk R, Bollen KA, Brembs B, Brown L, Camerer C, Cesarini D, Chambers CD, Clyde M, Cook TD, Boeck PD, Dienes Z, Dreber A, Easwaran K, Efferson C, Fehr E, Fidler F, Field AP, Forster M, George El, Gonzalez R, Goodman S, Green E, Green DP, Greenwald AG, Hadfield JD, Hedges LV, Held L, Ho TH, Hoijtink H, Hruschka DJ, Imai K, Imbens G, JPA I, Jeon M, Jones JH, Kirchler M, Laibson D, List J, Little R, Lupia A, Machery E, Maxwell SE, McCarthy M, Moore DA, Morgan SL, Munafó M, Nakagawa S, Nyhan B, Parker TH, Pericchi L, Perugini M, Rouder J, Rousseau J, Savalei V, Schönbrodt FD, Sellke T, Sinclair B, Tingley D, Zandt TV, Vazire S, Watts DJ, Winship C, Wolpert RL, Xie Y, Young C, Zinman J, Johnson VE. Redefine statistical significance. Nat Hum Behav. 2018;2:6-10.

33. Linde $C$, Bongiorni MG, Birgersdotter-Green $U$, Curtis $A B$, Deisenhofer I, Furokawa T, Gillis AM, Haugaa KH, Lip GYH, Van Gelder I, Malik M, Poole J, Potpara T, Savelieva I, Sarkozy A, ESC Scientific Document Group. Sex differences in cardiac arrhythmia: a consensus document of the European Heart Rhythm Association, endorsed by the Heart Rhythm Society and Asia Pacific Heart Rhythm Society. EuroPace. 2018;20:1565-ao.

34. Iorga A, Cunningham CM, Moazeni S, Ruffenach G, Umar S, Eghbali M. The protective role of estrogen and estrogen receptors in cardiovascular disease and the controversial use of estrogen therapy. Biol Sex Differ. 2017:8:33.

35. Niemann JT, Rosborough JP, Youngquist S. Is the tumour necrosis factor-alpha response following resuscitation gender dependent in the swine model? Resuscitation. 2008;77:258-63.

36. Kuhar $P$, Lunder $M$, Drevensek $G$. The role of gender and sex hormones in ischemic-reperfusion injury in isolated rat hearts. Eur J Pharmacol. 2007:561: 151-9.

37. Noppens RR, Kofler J, Grafe MR, Hurn PD, Traystman RJ. Estradiol after cardiac arrest and cardiopulmonary resuscitation is neuroprotective and mediated through estrogen receptor- $\beta$. J Cereb Blood Flow Metab. 2009;29:277-86.

38. Herring MJ, Oskui PM, Hale SL, Kloner RA. Testosterone and the cardiovascular system: a comprehensive review of the basic science literature. J Am Heart Assoc. 2013;2:e000271.

39. Safdar B, Stolz U, Stiell IG, Cone DC, Bobrow BJ, de Boehr M, Dreyer J, Maloney J, Spaite DW. Differential survival for men and women from out-of-hospital cardiac arrest varies by age: results from the OPALS study. Acad Emerg Med. 2014;21:1503-11.

40. Vigen R, O'Donnell Cl, Barón AE, Grunwald GK, Maddox TM, Bradley SM, Barqawi A, Woning G, Wierman ME, Plomondon ME, Rumsfeld JS, Ho PM. Association of testosterone therapy with mortality, myocardial infarction, and stroke in men with low testosterone levels. JAMA. 2013;310:1829-36.

41. Siddiqui AN, Siddiqui N, Khan RA, Kalam A, Jabir NR, Kamal MA, Firoz CK, Tabrez S. Neuroprotective role of steroidal sex hormones: an overview. CNS Neurosci Ther. 2016;22:342-50.

42. dos Santos RL, da Silva FB, Ribeiro RF Jr, Stefanon I. Sex hormones in the cardiovascular system. Horm Mol Biol Clin Investig. 2014;18:89-103.

43. Narayanan K, Havmoeller R, Reinier K, Jerger K, Teodorescu C, Uy-Evanado A, Navarro J, Huertas-Vazquez A, Gunson K, Jui J, Chugh SS. Sex hormone levels in patients with sudden cardiac arrest. Heart Rhythm. 2014;11:2267-72. 
44. Wise PM, Dubal DB, Rau SW, Brown CM, Suzuki S. Are estrogens protective or risk factors in brain injury and neurodegeneration? Reevaluation after the Women's Health Initiative. Endocr Rev. 2005;26:308-12.

45. Nakamura T, Xi G, Keep RF, Wang M, Nagao S, Hoff JT, Hua Y. Effects of endogenous and exogenous estrogen on intracerebral hemorrhageinduced brain damage in rats. Acta Neurochir Suppl. 2006;96:218-21.

46. Gibson CL, Constantin D, Prior MJ, Bath PM, Murphy SP. Progesterone suppresses the inflammatory response and nitric oxide synthase-2 expression following cerebral ischemia. Exp Neurol. 2005;193:522-30.

47. Topjian AA, Localio AR, Berg RA, Alessandrini EA, Meaney PA, Pepe PE, Larkin GL, Peberdy MA, Becker LB, Nadkarni VM, American Heart Association National Registry of Cardiopulmonary Resuscitation Investigators. Women of child-bearing age have better in-hospital cardiac arrest survival outcomes than do equal-aged men. Crit Care Med. 2010;38:1254-60.

48. Jouven X, Lemaitre RN, Rea TD, Sotoodehnia N, Empana JP, Siscovick DS. Diabetes, glucose level, and risk of sudden cardiac death. Eur Heart J. 2005:26:2142-7.

49. Arking DE, Sotoodehnia N. The genetics of sudden cardiac death. Annu Rev Genomics Hum Genet. 2012;13:223-39.

50. Bosson N, Kaji AH, Fang A, Thomas JL, French WJ, Shavelle D, Niemann JT. Sex differences in survival from out-of-hospital cardiac arrest in the era of regionalized systems and advanced post-resuscitation care. J Am Heart Assoc. 2016;5:e004131.

51. Dicker B, Conaglen K, Howie G. Gender and survival from out-of-hospital cardiac arrest: a New Zealand registry study. Emerg Med J. 2018;35:367-71.

\section{Publisher's Note}

Springer Nature remains neutral with regard to jurisdictional claims in published maps and institutional affiliations.

Ready to submit your research? Choose BMC and benefit from:

- fast, convenient online submission

- thorough peer review by experienced researchers in your field

- rapid publication on acceptance

- support for research data, including large and complex data types

- gold Open Access which fosters wider collaboration and increased citations

- maximum visibility for your research: over $100 \mathrm{M}$ website views per year

At $\mathrm{BMC}$, research is always in progress.

Learn more biomedcentral.com/submissions 